\title{
Irish dairy farmers' engagement with animal health surveillance services: Factors influencing sample submission
}

\author{
Lauren McFarland, ${ }^{1} \oplus$ Áine Macken-Walsh, ${ }^{2 *}$ Grace Claydon, ${ }^{2}$ Mícheál Casey, ${ }^{3}$ Alexander Douglass, ${ }^{1}$ \\ Guy McGrath, ${ }^{4}$ (1) and Conor G. McAloon ${ }^{1}$ (]) \\ ${ }^{1}$ School of Veterinary Medicine, University College Dublin, Belfield, Dublin, Ireland D04 W6F6 \\ ${ }^{2}$ Department of Agri-Food Business and Spatial Analysis, Rural Economy Development Programme, Teagasc, Athenry, Ireland H65 R718 \\ ${ }^{3}$ Regional Veterinary Laboratories Division, Backweston Campus, Department of Agriculture, Food and the Marine, Celbridge, Kildare, \\ Ireland $\mathrm{W} 23 \mathrm{X} 3 \mathrm{PH}$ \\ ${ }^{4}$ Centre for Veterinary Epidemiology and Risk Analysis, University College Dublin, Belfield, Dublin, Ireland D04 W6F6
}

\begin{abstract}
A high-quality animal health surveillance service is required to inform policy and decision-making in foodanimal disease control, to substantiate claims regarding national animal health status and for the early detection of exotic or emerging diseases. In Ireland, the Department of Agriculture, Food and the Marine provides partially subsidized testing of farm animal samples and postmortem examinations to the Irish agriculture sector (farmers) at 6 regional veterinary laboratories (RVL) throughout the country. Diagnoses and data from these submissions are recorded and reported monthly and annually to enable animal health monitoring and disease surveillance. In a passive surveillance model, both the veterinary practitioner and the farmer play a vital role in sample submission by determining which cases are sent to the laboratory for postmortem or diagnostic testing. This paper identified factors influencing Irish dairy farmers' decisions to submit carcasses to RVL. Behavioral determinants of the submission of samples where veterinary professionals are concerned has been studied previously; however, limited work has studied determinants among farmers. This study conducted qualitative analyses of decisions of Irish dairy farmers relevant to diagnostic sample submission to an RVL and to examine the herd-level characteristics of farmers that submitted cases to an RVL. The biographical narrative interpretive method was used to interview 5 case-study farmers who were classified nonsubmitters, medium, or high submitters to the postmortem service based on the proportion of on-farm mortalities submitted to the laboratory service in 2016. The data obtained from these interviews were supplemented and triangulated through dairy farmer focus groups. The data were
\end{abstract}

Received November 11, 2019.

Accepted May 25, 2020.

*Corresponding author: aine.mackenwalsh@teagasc.ie thematically analyzed and described qualitatively. In addition, quantitative analysis was undertaken. Data for herds within the catchment area of a central RVL were extracted, and a multivariable logistic regression model was constructed to examine the relationship between herds from which carcasses were submitted to the laboratory and those from which none were submitted. Results from the analysis show that the farmer's veterinary practitioner was the primary influence on submission of carcasses to the laboratory. Similarly, the type of incident, logistical issues with transporting carcasses to the laboratory, influence of peers, presence of alternative private laboratories, and a fear of government involvement were key factors emerging from the case-study interview and focus group data. Herd size was identified in both the qualitative and quantitative analysis as a factor determining submission. In the logistic regression model, herd size and increased levels of expansion were positively correlated with the odds of submission, whereas distance from the laboratory was negatively associated with odds of submission. These results identify the main factors influencing the use of diagnostic services for surveillance of animal health, signaling how services may be made more attractive by policy makers to a potentially wider cohort of users. Key words: passive surveillance, farmer decisionmaking, animal health policy

\section{INTRODUCTION}

A high-quality animal health surveillance service is required to inform policy and decision-making in disease control, substantiate claims regarding national animal health status, and detect early exotic or emerging diseases. In Ireland, the Department of Agriculture, Food and the Marine (DAFM) provides partially subsidized testing of farm animal samples and postmortem examinations to the Irish agriculture sector (farmers) at 6 regional veterinary laboratories (RVL) 
throughout the country. Currently, farmers pay a fee of approximately $€ 20$ for the postmortem examination of a calf or approximately $€ 70$ for the examination of an adult cow; both fees include the cost of carcass disposal (DAFM, 2020). Results from the RVL are issued to the farmer's private veterinary practitioner, from whom farmers receive the results with interpretive assistance provided by the veterinarian. Diagnoses and data from these submissions are recorded and reported monthly and annually to enable animal health monitoring and disease surveillance.

Ideally, surveillance data should be representative of the true frequency of disease within the population. Bias should be absent, with samples submitted equally from all regions, sizes and types of farms, and all disease presentations (Hueston, 1993). Passive surveillance or enhanced passive surveillance systems, defined as surveillance systems that rely on observer-initiated provision of animal health data (Hoinville et al., 2013), offer the advantage of being less expensive than active surveillance and can better function as an early warning system against disease (Mather et al., 2016). However, in a passive surveillance system, a proportion of bias can be expected given that unfiltered stakeholder case selection is the norm (Dórea et al., 2011). Similarly, under-reporting of cases, low sensitivity, and a lack of timeliness may all affect the usefulness of a passive surveillance system (Hadorn et al., 2008; Dórea et al., 2011).

To understand the effect of this bias and how it can be reduced, the factors influencing whether veterinarians and farmers choose to submit samples to the RVL need to be understood. Both the veterinarian and the farmer play a vital role in sample submission by determining which cases are sent to the laboratory for postmortem or diagnostic testing. For example, a carcass cannot be submitted to an RVL without the referral of a veterinarian. The factors behind the submission of samples from the veterinary profession's perspective (i.e., their propensity to submit and why they submit) has been studied previously. The veterinarians' perceived role in disease surveillance, their relationship with the particular laboratory, the type of case(s) with which they were presented, and the economics of cattle value and government support have been shown to be key factors in the propensity of veterinarians to submit samples from a particular farm (Robinson et al., 2012; Robinson and Epperson, 2013; Sawford et. al., 2013). Therefore, for this study, the focus was on dairy farmers and the factors influencing their decisions on laboratory submissions.

In a previous DAFM research project on the prevalence and etiology of calf diseases in expanding dairy farms, several farms failed to submit all eligible calf carcasses for postmortem examination despite free collection, free examination, and free diagnostics (M. Casey, Department of Agriculture, Food and the Marine, Celbridge, Kildare, Ireland, unpublished data). This suggests that cost and distance aren't the only factors affecting submission patterns, and that there is likely a complex thought process behind a farmer's decision to submit to the RVL, which hasn't previously been researched in Ireland.

Previous studies of factors influencing farmer decision-making have shown that farmers are not solely influenced by economic consequences (Van Asseldonk et al., 2010), but also by social and cultural consequences (Vanclay and Enticott, 2011; McAloon et al., 2017). Quantitative research techniques, such as the use of surveys, are useful in generating statistically representative data. However, qualitative methods such as interviews and focus groups are more appropriate for exploring values, perspectives, and prior experiences influencing management practices or choices (Kitzinger, 1995; Vaarst et al., 2002). The purpose of this study was to conduct qualitative and quantitative analyses of the decision-making and the herd characteristics of Irish farmers relevant to diagnostic sample submission to an RVL.

\section{MATERIALS AND METHODS}

Athlone Regional Veterinary Laboratory was chosen as the site for this study due to its size (largest), central geographic location nationally with a catchment uninterrupted by coast, and representativeness of samples received relative to the rest of the RVL in Ireland.

\section{Study Design}

Qualitative and quantitative methods were employed in study design. A qualitative method was incorporated to this study as the aim was to examine farmers' decisions to submit carcasses, and an in-depth approach to analysis would not be possible through a quantitative study alone (Christley and Perkins, 2010). For this study, a combination of narrative interviewing of case-study farmers and focus groups and quantitative data analysis was chosen to use different data sources and data types to draw conclusions on our research question. We used different data sources to triangulate research findings, where triangulation is defined as "the use of multiple methods or data sources in qualitative research to develop a comprehensive understanding of phenomena" (Patton, 1999, cited in Carter et al., 2014 , p. 545). Flyvbjerg (2014, p. 432) explains that among the advantages of quantitative, "large samples is breadth, while their problem is one of depth. For [quali- 
tative] case-study research, the situation is reverse. Both approaches are necessary for a sound development of social science."

Case studies have the capacity to shed light on the intricate interdependencies that culminate in human decision-making (Flyvbjerg, 2004). Case studies are highly useful for generating context-dependent social science knowledge that can be generalizable to other contexts and generating hypotheses about other contexts (Flyvbjerg, 2004). We employed a case-study approach to identifying farmer cases of interest to our study and qualitative interviewing as a method to investigate the cases in depth.

Qualitative interview data on the sensitive topic of on-farm deaths were obtained from one-on-one interviews with case-study farmers. A narrative approach to interviewing was used to yield highly specific and reliable data regarding the interviewees' actual lived experiences. An open-ended question was used to elicit the farmers' narratives, designed to allow farmers to identify the experiences that were important to them. This was followed with more specific questions posed by the interviewer, seeking details about parts of the narratives the farmers had just told. The narrative interviewing approach focused on the experiences of farmers when deciding to submit a carcass to the laboratory. We could identify through farmers' detailed descriptions of their experiences the factors influencing their decisions to submit or not.

These qualitative data were enriched by data generated by peer-to-peer discussion from the focus groups (Kitzinger, 1995; Gill et al., 2008). Focus groups offer researchers access to the inside views of groups of people who, due to their shared experience, knowledge, or socio-cultural orientation, discuss between them topics with familiarity, knowledge, and expertise. The focus groups were different than the narrative interviewing because, in contrast to the open-ended questions used for the interviews, the focus groups were facilitated to focus more directly on 3 questions regarding benefits associated with submitting carcasses to the RVL, hindrances or difficulties experienced when submitting to the RVL, and possible solutions. Such data are valuable for policy design, allowing for evidenced-based strategies to promote the benefits (valued by farmers) of RVL and identification of ways to encourage greater rates of submission.

Quantitative analysis of statistically representative data allows for more generalizable conclusions to be drawn from research. The aim of the quantitative analysis employed for this study was to ascertain whether herd-level variables (herd size, degree of expansion, and proximity to laboratories) were associated with the likelihood of a herd submitting a carcass to the RVL. The results of the quantitative analysis show attributes of nonsubmitters (herd size, degree of herd expansion, geographical proximity of RVL) that are consistent with the qualitative analysis.

\section{Participant Selection}

Interviews with Case-Study Farmers. Purposive (i.e., selective, nonrandom) sampling of 5 case-study farmers was carried out with the aim of representing farms with moderate and high submission rates and nonsubmitters. Two high submitters, 2 medium submitters, and 1 nonsubmitter were selected. The reason only 1 nonsubmitter was interviewed is because a second nonsubmitter could not be identified by either the research team or the gatekeepers used.

To select high and medium submitters, submissions to the RVL in 2016 were reviewed. First, dairy herds that had submitted more than 3 bovine carcasses in that year (excluding fetuses and perinates, which are examined free of charge) were selected. Next, submissions were reviewed to exclude multiple carcasses submitted together (i.e., on the same day and likely to be from a single disease outbreak). The mortality on each farm for 2016 was then reviewed to determine what proportion of that mortality the RVL had received. Farmers that had submitted over $30 \%$ of their mortality were defined as high submitters, whereas those submitting between 10 and $30 \%$ were classified as medium submitters. Farmers that had family working in the laboratory or were part of a research farm were excluded. Farmers were contacted by telephone to organize the interview.

Nonsubmitting herd owners were selected in a different manner because there were no records of submission to the laboratory for these farmers. First, advisors from Teagasc, an Irish agricultural advisory service, were contacted and asked to find dairy farmers who had not previously submitted to RVL. There was no database available from which to draw a purposive sample of farmers who had not previously submitted, representing, for instance, herd sizes or owner characteristics of interest to the study. Instead, Teagasc advisors were asked to identify from their own knowledge farmers who were unlikely to have submitted, to contact those farmers to verify they had not submitted, and to ask the farmers their consent to be contacted by researchers undertaking the study. No script was issued to the Teagasc advisors for use when contacting farmers.

The interviewees who were identified and consented to interview (using a participant information sheet and consent form) could therefore not be selected for particular characteristics; hence, they represent a variety 
Table 1. Characteristics of farmers selected for interview

\begin{tabular}{lll}
\hline Characteristic & $\begin{array}{c}\text { Number } \\
\text { of farmers }\end{array}$ & $\begin{array}{l}\text { Farmer number } \\
\text { (specified in } \\
\text { interview quotations) }\end{array}$ \\
\hline Age & 1 & 4 \\
$<40$ & 2 & $1,2,5$ \\
$40-55$ & 2 & 3 \\
$55-60$ & 2 & 3,4 \\
Herd size & 2 & 5 \\
$<100$ & 1 & 1,2 \\
$100-300$ & 1 & 1 \\
$>500$ & 1 & 2 \\
Distance from RVL ${ }^{1}$ in $\mathrm{km}$ & 3 & $3,4,5$ \\
$0-30$ & & $1,2,3$ \\
$30-60$ & 3 & 4,5 \\
$90-120$ & 2 & 4,5 \\
Job & & \\
Full time & & \\
Part time & 3 & $1,2,3$ \\
Marital status & 2 & \\
Single & & \\
Married & &
\end{tabular}

${ }^{1} \mathrm{RVL}=$ regional veterinary laboratories.

of demographic and geographic descriptors such as age, herd size, and location (Table 1). It transpired that all were male and had inherited the farm.

Focus Group Participants. Focus groups were undertaken with preformed discussion groups located in different distance bands from Athlone RVL, and all were part of Teagasc's Knowledge Transfer (KT) program. None of the case-study farmers interviewed for this study were part of the focus groups. Focus groups were implemented in 2 groups by the authors of this paper in cooperation with the groups' habitual facilitators (Teagasc KT advisors). The implementation of the method in the remaining 2 groups was undertaken by Teagasc KT advisors alone. The use of pre-existing focus groups was preferred as the participants were already comfortable with each other and were available during the time period of the study (Gill et al., 2008). Reflecting the purpose of focus groups as a data collection exercise, the aim of the focus groups was to access the views of the farmer participants and use these views to generate accurate hypotheses and generalizations about how the general farming population regards use of animal health surveillance services. Distinct from the interviews, which sought to elicit interviewees' lived personal experiences, the focus groups aimed to tap into farmers' inside and expert knowledge about farmers everywhere.

Discussion groups were selected in the same distance bands (proximal distance between location and the RVL) used for the quantitative analysis. Four focus groups were chosen to participate in the study; 1 was located in the 30 - to $60-\mathrm{km}$ distance band (zone), and the other 3 were located in the 0 - to $30-\mathrm{km}$ distance band. The groups were selected based on their proximity to Athlone and their willingness to participate. No information was sought on individual farmer behavior regarding submission of carcasses in advance of the focus groups. Although we do not have demographic data relating to the members of the discussion groups who participated in the focus groups, discussion groups in Ireland are commonly participated in by all livestock farmers, the vast majority of whom are male and over 50 yr old.

\section{Data Collection Structure: Individual Case-Study Interviews}

The interviewed farmers consented to the anonymized use of their personal details regarding carcass submission. A sociologist, the corresponding author who is trained in the biographical narrative interpretive method (BNIM) conducted telephone interviews with the farmers. Interviews were conducted by telephone rather than in person because of time limitations in a study that was conducted over a 3-mo period. Nonetheless, the interviewing method used is conducive to use by telephone; no documents or other artifacts are required in the interviewing process. The BNIM is an interview technique where the interviewee provides a narration of details of actual lived experiences (Wengraf, 2001) rather than hypothetical views or opinions. As we were interested in the factors that influenced farmers to submit or not, the BNIM was a useful method to elicit the lived experiences of farmers making those decisions. The interviewer triggered this by asking a single question aimed at inducing narrative (SQUIN) with no prompting to allow the interviewee to develop their own narrative without interruption (Wengraf, 2001). The SQUIN in this case was:

"As you know, I'm interested in how farmers make decisions to send or not send carcasses or fetuses to the lab. Can you tell me the story of when it happens that an animal dies on the farm?"

"Tell me the story" is a fixed part of the SQUIN, to induce narrative story-telling. "When it happens" was chosen for our SQUIN to avoid the farmer focusing on a sole event or the last event when he made a decision regarding submission. Specific questions were posed to the interviewees to ask more detail about the narrative they had just told once they had completed their narrative response to the SQUIN. The interviews took between $20 \mathrm{~min}$ and $1 \mathrm{hr}$ and were recorded, transcribed verbatim, and anonymized. It is important to note that 
due to the focused nature of the SQUIN, and possibly because interviews were conducted by phone rather than in person, the narratives elicited from interviewees could be quite short, particularly where farmers had few experiences of animal mortalities on their farms. Farmers signed consent forms for their participation in the interviews. The research ethics protocols were prescribed by Teagasc's Social Science Research Ethics Group.

\section{Focus Groups}

After the interviews were completed, 4 focus groups were conducted using specific focus group exercises (see Supplemental File S1, https://doi.org/10.3168/jds .2019-17889). In contrast to the open-ended narrative interviewing approach employed with case-study farmers, the focus groups centered on 3 focused questions about the benefits participating farmers associated with submitting carcasses to the laboratory, hindrances or difficulties they experienced when submitting to the laboratory, and possible solutions. Unlike the qualitative case studies, the focus groups were not audiorecorded and transcribed. The decision not to audiorecord and transcribe the focus groups was influenced by budgetary constraints and justified by the use of adhesive notes generated by participating farmers that would record the outcomes of the focus groups.

The design of the focus group method optionally included the development of personas of a farmer who submits most carcasses to the RVL (Supplemental Figure S1, https://doi.org/10.3168/jds.2019-17889) and a farmer that submits very little or nothing to the laboratory (Supplemental Figure S2, https://doi.org/ 10.3168/jds.2019-17889). A template for developing personas was provided to facilitators (Supplemental File S1). Personas are used as tool for participants to use their insider knowledge to develop stereotypical persons and their decisions. Likely decisions are identified and proofed by all the participants, providing a reliable data source for researchers. Two focus group facilitators did not use the persona template because the group's facilitator instead opted to facilitate a discussion of the likely factors influencing submission and nonsubmission (in turn), with reference to high submitter and low submitter hypothetical farmers. The facilitators who opted not to use the template reported that they were not familiar with and therefore uncomfortable using such templates and that they could generate a discussion on stereotypical persons without the use of the template. The exercises, with or without the use of the template, facilitated farmers to discuss specific questions: the benefits they as- sociated with submitting carcasses to the laboratory (Supplemental Figure S3, https://doi.org/10.3168/jds .2019-17889), hindrances/difficulties they experienced when submitting to the laboratory (Supplemental Figure S4, https://doi.org/10.3168/jds.2019-17889), and possible solutions (Supplemental Figure S5, https:// doi.org/10.3168/jds.2019-17889). They presented their replies on adhesive notes on a board. The benefits, hindrances, and potential solutions were then collated and discussed (Supplemental Figure S6, https://doi .org/10.3168/jds.2019-17889).

The focus groups consisted of 8 to 12 participants, and each lasted approximately $1.5 \mathrm{~h}$. Farmers reviewed and signed research ethics consent forms before starting the focus group. The research ethics protocols were prescribed by Teagasc's Social Science Research Ethics Group.

\section{Data Analysis}

Qualitative Analysis. The analytical aim of qualitative description is to report the facts and the meanings participants give to those facts (Sandelowski, 2000). The qualitative analysis conducted for this study had 2 elements: narrative interviewing of case-study farmers and farmer focus groups. The mode of analysis was qualitative description for both, but the qualitative data types and sources were different.

The transcripts of the narrative interviews were read repeatedly (by 3 authors), and discussions took place intermittently to share ideas regarding interpretations of the transcripts. The interview transcripts were in response to an open-ended question, and therefore differed significantly. Although the narrative data contained some interesting variations reported in the results section, across the data sets there were clear patterns of decision-making relevant to our research question. The 3 researchers examined and discussed the photographs of the adhesive notes that farmers produced in the focus groups. In contrast with the interviews, the focus groups contained answers to more direct questions. Therefore, the answers (provided by farmers in the form of adhesive notes) were easy to compare and contrast in the process of analysis.

We analyzed the interview transcripts together with the focus group data, identifying patterns across the data sets. To identify and trace the patterns, we used coding. Excerpts from the data relevant to a pattern were given a code name (Tracy, 2013). In analyzing both qualitative data sets, no preset codes were applied in the analysis, rather the codes were data derived (Sandelowski, 2000), which means that the researchers together interpreted the data to reach new, modified, 
and then final codes that described patterns in the data. In keeping with a qualitative descriptive approach (Sandelowski, 2000), we did not use a fixed interpretive framework to analyze the data. Rather, our approach was to identify patterns across the qualitative data set (interviews and focus groups) and to report a summation of those patterns. We identified all data (and patterns) in the data set to answer our research question: What are the factors determining dairy farmers' decisions to submit samples to their RVL?

In qualitative descriptive analysis, Sandelowski (2000) recommends that representation of data should be organized in a way that best fits the data. Employing this approach, the patterns are presented in a selection of headings under which the data can be comprehensively and logically presented. Consistent with the recommendations of Sandelowski (2000), we describe the patterns and also illustrative quotations from the interview transcripts. The adhesive notes from the focus groups are described in the results section, and a selection of the notes are presented in Supplemental File S1 (https: //doi.org/10.3168/jds.2019-17889). All of the data pertaining to our research question are reported in this paper, and instances where interview data and focus group data diverge is reported (a likely outcome due to the different methodologies employed).

Quantitative Data Analysis. Herd size, degree of expansion, and proximity to laboratories were key questions of interest to Ireland's DAFM, in the context of expanding dairy herds after quota abolition and planned restructuring of RVL services. The aim of the quantitative analysis was to ascertain whether any of these herd-level variables were associated with the likelihood of a herd submitting a carcass to the RVL. This analysis would allow for more generalizable conclusions to be drawn from the qualitative analysis with regard to herd size, degree of expansion, and geographical location.

Quantitative analysis was carried out using a multivariable logistic regression model. Data for dairy herds within the Athlone RVL catchment area were extracted from the national Animal Identification and Movement System for Irish cattle, including herd size in 2004 and 2015 and distance zone from Athlone RVL (0-30, 30-60, and 90-120 km). Herds that had submitted to Athlone RVL in 2016 were identified by matching with submission records. Herds with a herd size $<20$ in 2015 were excluded, and all data were anonymized before passing to the researchers.

From these data, several additional variables were created before analysis. First, a binary variable was created based on whether that farm had submitted a carcass to the laboratory in 2016. This variable was used as the outcome of interest. Next, several summary explanatory variables were created. First, change in herd size was created by calculating the proportional change in herd size for each herd in the data set as:

(herd size 2015 - herd size 2004)/herd size 2004.

This variable was then converted to a categorical variable according to the quintiles of the population. Similarly, an additional categorical variable describing herd size in 2015 was also created, again according to the quintiles of the population.

Each variable was first screened in a univariable model. Those where $P<0.2$ were offered to the multivariable model in order of their univariable $P$-value, with the variable with the lowest $P$-value from the univariate analysis added first. Before the addition of each variable, the correlation between that variable and existing variables in the model was calculated. When variables were highly correlated $(>0.8)$ only one variable was selected, with the variables resulting the in the best model fit, as determined by the lowest Akaike information criterion (AIC), retained for addition to the model. Similarly, when the same information was contained within 2 different variables, for example change in herd size as a continuous or categorical variable, the decision of which variable to include was based on the model with the lowest AIC.

After the addition of each variable, the $P$-values for all of the variables in the model were recalculated, and only those where $P<0.05$ were retained in the final model. Data analysis was conducted in R-studio, version 1.1.419 (R Core Team, 2017).

\section{RESULTS}

\section{Qualitative Results}

Here we present themes from the analysis in sections using quotes and adhesive note excerpts from interview and focus group data. Quotations from farmer interviews contain a reference to farmers, identified by a number (eg., farmer 1, farmer 2). In Table 1, the numbered farmers are specified according to the following characteristics: age, herd size, distance from RVL, job, and marital status.

It is evident from the descriptive analysis of the qualitative data that farmers are reluctant to send every carcass to the laboratory, and to make the decision to submit or not, farmers were influenced by the factors described below. Suggestions provided by farmers to enhance rates of submission are also presented.

The descriptive analysis is presented under the following headings: influence of the veterinarian, type of incident, difficulty in transporting carcasses to the 
RVL, herd size and experience, influence of peers, alternative laboratories, fear of government involvement, and farmers' views on how to enhance submission rates.

\section{The Influence of the Veterinarian}

The veterinary practitioner plays an important role in the farmer's life. Farmers interviewed mentioned developing a sense of trust with their veterinary practitioner over time. This relationship has a significant role in the decision on whether to submit samples to the laboratory. For many farmers, the veterinary practitioner is the first person they approach if they have any signs of an issue on the farm:

"the minute I sense there's a problem then I call in the vet" (Farmer 1).

"I think the relationship with the vet is really important. Like where there's a strong relationship with the vet, they (farmers) tend to be more proactive about their health or the vet seems to have a bigger influence on them" (Farmer 4).

Accordingly, farmers relayed that if their veterinarian thought it was a good idea for the animal to go to the laboratory, they were likely to submit the carcass:

"if they tell me they (the vet) want me to go to the veterinary lab, I'll go to the veterinary lab" (Farmer 1).

Farmers gave several reasons why they felt the veterinary practitioner would choose to send an animal to the laboratory. In the first instance, this was related to whether the veterinarian had been unable to diagnose a cause of death for a deceased animal, in which case the decision may be made to send the carcass to the RVL for a postmortem:

"sometimes they can have a look and tell you. And then if not you might, usually the vet would recommend that the carcass would go to the veterinary lab so they'd run tests on it" (Farmer 4).

However, an undiagnosed cause of death on its own was not enough to result in the submission of a carcass to the laboratory. Farmers also highlighted that some veterinarians were more motivated in sending animals to the laboratory because they were more proactive in reaching a diagnosis. In contrast where the veterinarian was not particularly interested in reaching a diagnosis, the farmer could be less likely to submit the carcass: "our vet tends to be very proactive and that's how we'd err on the side of caution and find out what's happened. Whereas I would think even talking to farmers that if the vet wasn't that bothered about sending the animal, the farmer mightn't be that bothered" (Farmer 4).

Each focus group viewed the role of the veterinary practitioner in carcass submissions in much the same way as the farmers interviewed. The veterinarian's involvement was identified as a possible hindrance, as an extra middleman in the process of submission. It was stated that the veterinary practitioner could forget about contacting the farmer when they received the results, particularly during busy times of the year. Farmers suggested the laboratory send a direct text or email to the farmer to confirm the report had been sent to their veterinarian or provide an option for farmers to deal directly with the laboratory in submitting and receiving their results.

\section{Type of Incident}

The interview data showed that the type of case and presentation had a role in whether farmers submitted to the laboratory. In many cases the farmer themselves, or their own veterinary practitioner would have made a diagnosis before the animal had died. In these cases, farmers did not believe it was worthwhile transporting the animal to the laboratory for a full postmortem, particularly if they were treating them for a potentially fatal illness:

"9 times out of 10 (if) there's an animal dies on me, I'll know what they died from, like I'll be treating them or something like" (Farmer 3).

In contrast, if an animal represented a perceived unusual presentation they were more likely to bring the carcass to the laboratory. In the following quote the farmer describes his reasons for taking a particular animal to the laboratory:

“there's a particular presentation with that you'd be familiar with it didn't look like that, it didn't look like anything I'd seen before" (Farmer 1)

Farmers interviewed were reluctant to send a single mortality case to the laboratory unless they were very alarmed or curious as to what had happened. An occasional death wasn't seen as a reason for untoward concern, particularly on farms with large herd sizes: 
"if a cow or a calf or something popping their clogs [dying] every now and again, like I know I personally wouldn't be messing about and going to the lab with them" (Farmer 3).

In contrast, if they started to notice a pattern in the deaths or had more than one death in a short time period they were likely to bring the animal for a postmortem:

"unless we have an issue where we had a couple of them coming in a twenty-four-hour period it wouldn't be a cause for alarm for us anyway"

(Farmer 2).

Much of the reasoning behind taking single or multiple deaths to the laboratory was related to whether the farmer perceived the mortality as the start of a herd outbreak, causing further losses:

"Sure it wouldn't make any difference to the animal and it's not going to affect the performance of the rest of the herd" (Farmer 2).

In line with this, particular ages and types of animals (e.g., stillborn calves and fetuses) were regularly taken to the laboratory, whereas older stock were less likely to be submitted:

"we haven't had issues with older stock. So it's only been calves or foetuses that we've sent to the veterinary lab" (Farmer 4).

The increased submission of young stock was explained by farmers as wanting to prevent increased losses in the future, particularly in spring when something such as an abortion storm could cause a lot of mortality:

"you'd always be fearful of some sort of infectious disease or particularly like if it was something like an abortion, you'd be afraid it might be salmonella or something, you could get an abortion storm" (Farmer 4).

"It's just to find out like, that's the biggest thing, so you know what's wrong or, because in case it might be leading into something more serious like or something that might affect more animals" (Farmer 4).

The type of incident theme arose in the focus groups in a similar way to how it arose in the interviews. Farmers were identified as benefiting from submissions, particularly in the event of an unexplained death or multiple cases, and it was agreed that younger stock were most likely to be submitted by farmers. Farmers' motivation to submit was identified the desire to diagnose the disease or cause of death to gain peace of mind and to prevent further outbreaks at a herd level by selecting the correct treatment or vaccination.

\section{Difficulty Transporting Carcasses to the RVL}

Case-study farmers repeatedly mentioned the difficulty in submitting carcasses to the laboratory. Currently, the farmer must bring the carcass to the laboratory or arrange their own help and transport to do so. This was seen as a significant inconvenience, which would deter farmers submitting samples to the laboratory:

"the only thing that would stop a farmer from sending animals to the lab is the hassle of it" (Farmer 3).

Consequently, case-study farmers claimed they would use the service more if they were located nearer to the RVL:

"if you had a lab maybe close beside you, you probably would go, you would go quicker like" (Farmer $5)$.

In addition, traveling with a carcass to the laboratory can be more difficult depending on the age of the animal. A fetus or calf is much easier to transport than a mature animal:

"if I have to bring an animal down to the lab, like unless it's a lamb or a calf or something small like, you know that you could throw in the boot of the car or something like that but ... if you were to bring a beast that's, you know that's a year-old plus, like that's a big, big ... job like" (Farmer 3).

In contrast, some farmers viewed the knackery (slaughterhouse for animals not for human consumption) as a more accessible and convenient means of disposing of dead stock:

"I can call the knackery and they come and they collect them and I just give them the cheque and that's the end of it. Whereas I suppose to go, to make an appointment with my vet, drive and maybe wait a half an hour, an hour to do the paperwork and have 
the animal removed from the trailer. It takes time and to be honest unless there was something that I was extremely worried about" (Farmer 2).

Farmers usually have daily chores to carry out, with little time for dealing with unexpected events such as the death of stock. Many dairy farmers are particularly busy in spring when their animals are calving. This may be a time of increased on-farm mortality that coincides with a period of increased workload for the farmer. This means that busy farmers may not submit as much as they would during quieter times of the farming year. However, one farmer claimed that irrespective of how busy he was, if he started seeing patterns or multiple cases on his farm, he would submit to the laboratory in an effort to identify the cause and hopefully prevent it reoccurring:

"if it's a case that I got a second one then it wouldn't matter how busy I was somebody would be sent if I couldn't go myself to the veterinary lab" (Farmer $1)$.

The interviews indicated that the working profile of a farmer may be a factor in how much time they have available to make laboratory submissions. The interviewed farmers believed that if the farmer is only part time (2 interviewees were part-time farmers), they would be less likely to submit carcasses. In Ireland, the majority of all drystock (beef and sheep) farmers work on their farms part time, and some dairy farmers work on their farms part time. Part-time farmers would have to take time off work to submit carcasses and may not find the animal until after the laboratory is closed:

"they work Monday to Friday, their farming is done in the morning, evening and weekends. They are not there most of the time" (Farmer 1).

This was in contrast to full-time farmers who rely on dairying as their main source of income and can perceive the loss of an animal as a serious threat to their livelihood:

"and people who do nothing else do not mess around for the most part; like they are serious about what they are at" (Farmer 1).

All focus groups reflected the interviewed farmers' views on the difficulty of getting the carcass to the RVL, which was perceived as contrasting with the userfriendly service provided by the knackery. The focus groups also raised the issue of farmers not holding a suitable license or transport equipment to transport carcasses to the laboratory. One farmer mentioned that having to take the animal in one's own vehicle could cause a biosecurity issue on the farm. Farmers felt a solution to the issue could be for a collection service to be provided or a designated collection point where carcasses could be left. They thought a refrigeration unit would be ideal as this would provide a solution to carcass submission during times when the RVL is closed. If an animal died at the weekend the farmers would be less likely to submit a carcass, so they recommended some form of weekend service should be available, especially in spring when they are particularly busy.

Several farmers in the focus groups had never submitted to the laboratory and did not know the procedure, whereas others were not aware of the range of tests available and felt the service would benefit from increased advertising. They suggested an information night about the laboratory should be held, with a chance to meet the veterinarians involved. One group felt the service was impersonal and thought the farmer should see the postmortem carried out.

Participants in the focus groups suggested that farmers could experience a degree of frustration when results were returned as inconclusive. In these cases, farmers believed that results should be externally referred to get a definitive result. Farmers felt that the service would be improved if they were able to access visual information from the postmortem and if they were able to access resulting reports on the prevalence of disease in their local area through a leaflet, social media, or agricultural newspapers.

\section{Herd Size and Experience}

Interviews with case-study farmers indicated that farmers with a larger herd size tend to see more disease and death on their farm compared with a farmer with a smaller herd size. Interviewed farmers felt that those with larger herd sizes would have greater experience:

"we'd have an awful lot more experience because by the time we've hit year ten we've gone through his entire life time of stock" (Farmer 1, referring to the smaller herd-size farmer).

Hence, farmers with a larger herd size tend to have experienced more animal deaths. It is possible that they may be used to, and accept, a higher level of mortality on their farms, which could decrease their submission rates:

"dealing with what I am, which is a relatively big number (of animals) and then you're talking to somebody (who) for arguments sake has twenty five 
percent of that, he'd have a heart attack if something dies now, like we just regard it as pretty standard practice (to lose occasional animals)" (Farmer 1).

Participants in the farmer focus groups felt that a farmer who is likely to submit is younger, whereas a farmer who did not submit was likely to be greater than $60 \mathrm{yr}$ old. Submitting farmers were seen as running larger dairy farms compared with nonsubmitters who they thought would be beef or suckler farmers. Nonsubmitters were perceived as likely to live at a distance of greater than $30 \mathrm{~km}$ from the laboratory were seen as less likely to submit. Farmers who didn't submit were likely to have a lower level of educational attainment than submitters. Finally, submitters were viewed as likely to be married, possibly with children. Nonsubmitters were perceived as more likely to be single.

\section{Influence of Peers}

Farming is a close-knit sector where farmers rely on each other to share advice to improve their farm management and animal health. This advice can come from older generation as well as peers. In Ireland, this is particularly evident in the dairy sector with several farmers being involved in organized, funded discussion groups. These groups create a place where information can be shared and questions answered by people in similar situations, who may have seen and dealt with problems another farmer hasn't:

"that's another kind of window of information that can you'd throw something up and very often you throw something out to the lads there and some of the lads puts their hands up and they've come across the same thing" (Farmer 1).

Farmers feel these groups are very influential in the decisions they make on their farms, particularly if the majority of the group are doing something different:

"if two guys in a discussion group are doing something I guarantee you by the second or third year the only one or two that aren't doing it will be asked every single time (by the other group members) why [...] aren't you doing that" (Farmer 1).

The influence of peers didn't emerge in the focus group data. This is not surprising considering that the focus groups were conducted among peers, therefore participants may have been logically less inclined to focus on the factor of peer influence (unlike the confidential setting of one-on-one interviews) without being expressly facilitated to do so.

\section{Alternative Laboratories}

Many private companies offer analysis of samples, providing farmers with alternatives to the DAFM laboratories. These companies offer a wide range of tests, and many farmers feel they are easier to use as they already avail of their services for other reasons:

"the place we send the milk to, they do a test every, every four months you pay for a test and they can tell you through the milk if you have like IBR, BVD or Lepto or that sort of things" (Farmer 4).

However, currently the RVL represents the only laboratory available in Ireland for the completion of postmortem examinations on farmed animals:

"when I'm worried that I have an IBR or BVD or some kind of infectious disease I would have choices but I'm not too sure if there's too many other places that would do an actual autopsy on an animal" (Farmer 2).

The farmers participating in the focus groups felt that the RVL should better advertise their services. The fact that RVL competitors provided some similar services for diagnostic testing at a cheaper price and didn't require the additional cost of veterinary referral was seen as hindering the use of RVL.

\section{Fear of Government Involvement}

The DAFM is a government department and the RVL are fully embedded within it. Two farmers interviewed believed this is an issue as they fear a bad laboratory result could lead to a farm investigation and negative consequences for the farmer:

"if you've been unlucky enough to get hit for example by TB and Brucellosis and you've been cleared out people will be reluctant to go to the lab on the off chance that something's going to show up and [...] there's a bigger problem" (Farmer 1).

Many farmers in the focus groups were wary of submitting to the RVL as it is under government stewardship. They believed this could lead to follow-up inspections on their farm if a significant result for one of their carcasses was obtained. They felt this could be remedied by keeping farmers' details anonymous and ensuring that the farmer be notified before a department veterinarian arriving on the farm. They also thought the farmer's own veterinary practitioner should be able to carry out the tests. 
Table 2. Results of multivariable logistic regression model on factors associated with whether a farm submitted a carcass to the regional veterinary laboratory (RVL) in 2016

\begin{tabular}{lccccc}
\hline Variable & Estimate & SE & Odds ratio & $95 \%$ CI & $P$-value \\
\hline Intercept & -2.351 & 0.259 & & & \\
Herd size in 2015 & 0.004 & 0.001 & 1.004 & $(1.002,1.005)$ & $<0.001$ \\
$\begin{array}{l}\text { Level of expansion } \\
<-15.4 \%\end{array}$ & Referent & & & & \\
-15.4 to $2.9 \%$ & -0.056 & 0.305 & 0.945 & $(0.52,1.718)$ & 0.853 \\
2.9 to $16.8 \%$ & 0.216 & 0.284 & 1.241 & $(0.711,2.167)$ & 0.447 \\
16.8 to $32.3 \%$ & 0.428 & 0.275 & 1.534 & $(0.895,2.629)$ & 0.119 \\
$>32.3 \%$ & 0.622 & 0.275 & 1.862 & $(1.087,3.19)$ & 0.024 \\
Distance from RVL & & & & & \\
$\quad<30 \mathrm{~km}$ & Referent & & & & $<0.001$ \\
$30-60 \mathrm{~km}$ & -0.926 & 0.183 & 0.396 & $(0.277,0.567)$ & $<0.001$ \\
$60-90 \mathrm{~km}$ & -3.033 & 0.232 & 0.048 & $(0.031,0.076)$ & $<0.001$ \\
$90-120 \mathrm{~km}$ & -5.824 & 0.604 & 0.003 & $(0.001,0.01)$ & \\
\hline
\end{tabular}

\section{Farmers' Views on How to Enhance Rates of Submission}

In response to the focused question about how to enhance farmers' submission rates, the focus group data provided the following insights. Opening hours and submission times were a significant issue with many farmers unaware of the specific opening hours. They felt that not accepting carcasses over a lunch break was unacceptable and that at least one member of staff should be available to take the carcass in if a submission were to arrive during this time. Other recommendations included advertisement of submission times and extended opening hours, particularly in spring. Previous bad experiences of the RVL affected submission with many farmers mentioning issues such as a prolonged wait for results compared with competitors (i.e., private laboratories for antemortem tests), inconclusive results, and not receiving any results. Possible solutions suggested for these issues included explaining the theory and processing of the tests to farmers, issuing results more quickly (preferably directly to farmers), providing an estimated time for the availability of results, or using an online service where farmers could track the progress of the case.

\section{Quantitative Results}

The results of the final multivariable logistic regression model are shown in Table 2. Herd size and degree of expansion were both positively associated with submission to the laboratory. Each 1-cow increase in herd size resulted in a 1.004 increase in the odds of submission. Among expansion quintiles, the lowest odds of submission were observed in herds that had a herd size of $85 \%$ to $102.9 \%$ of their herd size in 2004 ; however, this was not significantly different than herds that had the greatest degree of herd contraction $(<85 \%$ of their
2004 herd size). Increases in categories above this led to consistent increases in the coefficient for that category with the highest increase observed for herds growing by 17 to $32 \%$, however, the only significant difference relative to the reference group was observed in the largest growth quintile, that is for herds that that had grown in size by more than 32\% relative to their 2004 herd size. Finally, the distance from the laboratory was negatively associated with submission. After categorizing herds according to distance bands from Athlone RVL into $30-\mathrm{km}$ bands $(0-30,30-60,60-90$, and $90-120 \mathrm{~km})$, there were considerable decreases in the odds ratios of submission with each consecutive distance band.

\section{DISCUSSION}

Previous qualitative work conducted internationally has focused on the factors influencing the decision of the veterinarian to submit samples to the veterinary laboratory. To our knowledge this is the first qualitative study of the factors affecting the decisions of farmers to submit carcasses to the RVL. Limitations of the study are that case-study interviews were conducted by phone rather than in person and there is a relatively small sample size where the qualitative research exercises are concerned. However, it is also the case that large sample sizes are not typically used when conducting qualitative research; and triangulation was used to show how factors influencing decision-making presented in this paper were recurrent across both interview and focus group data as well as quantitative analysis.

Passive surveillance methods vary significantly between countries, particularly with respect to the level of government funding provided for such surveillance activities. Nonetheless, it is interesting to note that there are many similarities between the factors identified in international studies of veterinarians and our study, where farmers were the primary focus. 
In separate studies of veterinarians in Northern Ireland and Mississippi, the relationship between the veterinarian and pathologist was a key factor determining whether veterinarians were likely to submit samples to the laboratory. It was deemed important that pathologists were 'interested and cared about the case' (Robinson et al., 2012; Robinson and Epperson, 2013) which was associated with a trustful and close relationship between the veterinarian and veterinary pathologist. Similarly, in our study, the farmers included in our qualitative analysis highlighted the key role of the farmer-veterinarian relationship (echoing Vanclay and Enticott, 2011). Farmers interviewed and involved in focus groups spoke positively about their own 'proactive' veterinary practitioner who was keen to get a definitive diagnosis (and therefore submit samples to the laboratory), versus the veterinarians of acquaintances who they suggested were less interested in reaching a diagnosis.

However, the farmer-veterinarian relationship could also dissuade farmers from submitting samples to the laboratory. Our interviewees highlighted a high level of trust in their veterinarian and indicated a willingness to accept a clinical diagnosis without laboratory confirmation. This same finding has been reported previously from the viewpoint of veterinarians (Robinson and Epperson, 2013). Sawford et al. (2013) argued that cattle veterinarians are an underused resource in terms of emerging infectious disease surveillance (Sawford et al., 2013). Further studies of Irish livestock veterinarians are required to fully understand the decision-making process for veterinarians.

Interviewees in the present study reported that the type of case may affect the likelihood of whether a carcass is submitted. Farmers were more likely to take cases to the laboratory if multiple animals were affected or if the presentation was perceived to be something that might signal the beginning of an outbreak for the herd. Similarly, in Alberta, Sawford et al. (2013) found that presentations with multiple animals affected or those in which the diagnostics were likely to have direct clinical consequences were more likely to be submitted to the laboratory. Interestingly, a quantitative study from the United Kingdom found that the type of syndrome was likely to affect the probability of either carcass or biological sample submission. For example, enteric syndromes were much more likely to be submitted than neurological syndromes (Gilbert et al., 2014). These findings support the idea that the sensitivity of the surveillance system is likely to vary between different disease presentations.

Farmers in our study highlighted a range of logistical difficulties associated with the submission of samples to the laboratory. These related primarily to transport of carcasses, but also related to RVL opening hours. These factors were evident in individual interviews and focus groups and further supported by the finding in our quantitative analysis, where there was a statistically significant negative association between distance to the laboratory and the probability that a farmer would submit. Previous studies have reported the economic cost of laboratory submission as a barrier to submission (Sawford et al., 2013). In Ireland, RVL services are heavily subsidized by the government with a much lower cost to the farmer for postmortem examinations. However, there is a significant opportunity cost incurred by the farmer when they are required to transport the carcass the laboratory. This cost is perhaps higher in seasonal calving systems such as in Ireland, because the majority of illnesses and mortality would be expected to coincide with the periparturient period. In a seasonal system, the calving period is a time of intense workload for farmers. If farmers decide to submit to the laboratory at this time, a significant associated time cost is incurred, as demonstrated by the results presented in this paper.

Farmers in our study reported that there was an expected level of disease and mortality on their farm as a direct consequence of the number of animals on the farm. Sawford et al. (2013) reported that, according to Alberta veterinarians, there was an "expected level of disease" among farmers that varied from farm to farm. The farmers in our study suggested that for a smaller farmer, deaths may be seen less frequently, perhaps taken more seriously, and therefore, be more likely to be taken to the laboratory. However, this finding was not supported by the other components of the study. Farmers in our study suggested that nonsubmitting farmers were likely to be older and with smaller herds. Similarly, the final multivariable logistic regression model demonstrated a positive association between herd size and the odds of submitting a sample to the RVL. The qualitative and quantitative analyses support the idea of younger progressive farmers with larger herds being more likely to submit. Accordingly, our logistic regression model also found that farmers with a higher level of expansion were more likely to submit samples to the laboratory. Such expansion could also reflect the farmer type; however, it might also reflect a greater level of mortality on these farms. In these cases, increases in mortality could be attributed to the fact that some proportion of that expansion may be attributed to animal purchase. Newly introduced cattle to the herd present an opportunity for new diseases to be introduced to the farm, which could lead to increased mortality. Alternatively, many dairy farms may undergo expansion primarily through the retention of homebred animals. In this scenario, increases in morbidity and mortality 
might be anticipated if the increase in animal numbers is not accompanied by proportional increases in housing, infrastructure, or labor units.

The role of peers was highlighted among interviewed farmers as important in what they did generally, but also with regard to submission of samples. In this respect it was suggested that if other farmers within a discussion group tended to submit samples to the RVL, it was likely to inspire others within the group to do the same. The effect of such social norms in influencing farmer behavior has been recognized within the framework of the theory of planned behavior (Ajzen, 1991) when applied to disease control (Roche et al., 2015). Other authors have discussed a similar finding within the framework of cultural and social capital in disease control. In this context, farmers place value in doing the right thing (Vanclay, 2004), in being a good farmer as a form of cultural capital, as well as being perceived as a good farmer as a form of social capital (McAloon et al., 2017).

Finally, our analyses found that farmers were concerned about the potential negative consequences of a laboratory diagnosis on their farm, given that the RVL are run by DAFM (a government department). This finding is supported by other observations from studies of veterinarians. Robinson and Epperson (2013) reported that farmers were believed to be negatively influenced if there was a possibility of confirming a disease with external implications for their farm business. Interestingly, in that study, focus group participants (cattle veterinarians) gave an example of potentially zoonotic conditions such as salmonellosis. Such a finding might have important implications for the surveillance of zoonotic diseases.

\section{CONCLUSIONS}

The aim of this study was to investigate factors determining dairy farmers' decisions to submit samples to their RVL. The study identified the following factors as determining farmers' decisions: the role of their veterinarian, the type of presentation, difficulty in transporting samples to the laboratory, herd size and experience, the influence of peers, the presence of alternative laboratories, and the fear of government. In addition, our quantitative analysis demonstrated that distance to the laboratory was negatively associated with the probability of submitting samples to the laboratory, whereas herd size and the degree of expansion were positively associated with submission. These findings are important in supporting national surveillance programs and optimizing the relevance and effectiveness of the laboratory supports, if these are to be the main source of passive (scanning) surveillance data.

\section{ACKNOWLEDGMENTS}

Some of the qualitative data for this study were collected as part of a DAFM-funded summer placement scheme for University College Dublin undergraduate veterinary medicine students. Further data collection and analysis were conducted as part of the Surveillance, Welfare, and Biosecurity project funded by DAFM (RSF 17/S/230). The authors thank the anonymous reviewers for their valuable comments. The authors have not stated any conflicts of interest.

\section{REFERENCES}

Ajzen, I. 1991. The theory of planned behavior. Organ. Behav. Hum. Decis. Process. 50:179-211. https://doi.org/10.1016/0749 -5978(91)90020-T.

Carter, N., D. Bryant-Lukosius, A. DiCenso, J. Blythe, and A. J. Neville. 2014. The use of triangulation in qualitative research. Oncol. Nurs. Forum 41:545-547.

Christley, R. M., and E. Perkins. 2010. Researching hard to reach areas of knowledge: Qualitative research in veterinary science. Equine Vet. J. 42:285-286. https://doi.org/10.1111/j.2042-3306 .2010.00074.x.

DAFM (Department of Animals, Food and the Marine). 2020. RVL post mortem charges. Accessed Jan. 30, 2020. https:// www.agriculture.gov.ie/media/migration/animalhealthwelfare/ labservice/RVLPostMortemCharges31032014.pdf.

Dórea, F. C., J. Sanchez, and C. W. Revie. 2011. Veterinary syndromic surveillance: Current initiatives and potential for development. Prev. Vet. Med. 101:1-17. https://doi.org/10.1016/j.prevetmed .2011.05.004.

Flyvbjerg, B. 2004. Five misunderstandings about case-study research. Pages 420-434 in Qualitative Research Practice. C. Seale, G. Gobo, J. F. Gubrium, and D. Silverman, ed. Sage, London and Thousand Oaks, CA.

Gilbert, W. H., B. N. Häsler, and J. Rushton. 2014. Influences of farmer and veterinarian behaviour on emerging disease surveillance in England and Wales. Epidemiol. Infect. 142:172-186. https: //doi.org/10.1017/S0950268813000484.

Gill, P., K. Stewart, E. Treasure, and B. Chadwick. 2008. Methods of data collection in qualitative research: Interviews and focus groups. Br. Dent. J. 204:291-295. https://doi.org/10.1038/bdj.2008.192.

Hadorn, D. C., S. S. Haracic, and K. D. Stärk. 2008. Comparative assessment of passive surveillance in disease-free and endemic situation: Example of Brucella melitensis surveillance in Switzerland and in Bosnia and Herzegovina. BMC Vet. Res. 4:52. https://doi .org/10.1186/1746-6148-4-52.

Hoinville, L. J., L. Alban, J. A. Drewe, J. C. Gibbens, L. Gustafson, B. Häsler, C. Saegerman, M. Salman, and K. D. C. Stärk. 2013. Proposed terms and concepts for describing and evaluating animalhealth surveillance systems. Prev. Vet. Med. 112:1-12. https://doi .org/10.1016/j.prevetmed.2013.06.006.

Hueston, W. D. 1993. Assessment of national systems for the surveillance and monitoring of animal health. Rev. Sci. Tech. 12:11871196.

Kitzinger, J. 1995. Qualitative research: Introducing focus groups. BMJ 311:299. https://doi.org/10.1136/bmj.311.7000.299.

Mather, A. E., R. Reeve, D. J. Mellor, L. Matthews, R. J. Reid-Smith, L. Dutil, D. T. Haydon, and S. W. J. Reid. 2016. Detection of rare antimicrobial resistance profiles by active and passive surveillance approaches. PLoS One 11:e0158515. https://doi.org/10 .1371/journal.pone.0158515.

McAloon, C. G., Á. Macken-Walsh, L. Moran, P. Whyte, S. J. More, L. O'Grady, and M. L. Doherty. 2017. Johne's disease in the eyes of Irish cattle farmers: A qualitative narrative research approach 
to understanding implications for disease management. Prev. Vet. Med. 141:7-13. https://doi.org/10.1016/j.prevetmed.2017.04.001.

Patton, M. Q. 1999. Enhancing the quality and credibility of qualitative analysis. Health Serv. Res. 34:1189-1208.

R Core Team. 2017. R: A language and environment for statistical computing. R Foundation for Statistical Computing, Vienna, Austria. Accessed Mar. 5, 2020. https://www.R-project.org/.

Robinson, P. A., and W. B. Epperson. 2013. Farm animal practitioners' views on their use and expectations of veterinary diagnostic laboratories. Vet. Rec. 172:503. https://doi.org/10.1136/vr .101366 .

Robinson, P. A., W. B. Epperson, C. L. Huston, L. W. Pace, R. W. Wills, and A. G. Cosby. 2012. Factors influencing diagnostic sample submission by food animal veterinarians in Mississippi. Vet. Ital. 48:31-39.

Roche, S. M., A. Jones-Bitton, M. Meehan, M. Von Massow, and D. F. Kelton. 2015. Evaluating the effect of Focus Farms on Ontario dairy producers' knowledge, attitudes, and behavior toward control of Johne's disease. J. Dairy Sci. 98:5222-5240. https://doi .org/10.3168/jds.2014-8765.

Sandelowski, M. 2000. Whatever happened to qualitative description? Res. Nurs. Health 23:334-340. https://doi.org/10.1002/1098 $-240 \mathrm{X}(200008) 23: 4<334:: \mathrm{AID}-\mathrm{NUR} 9>3.0 . \mathrm{CO} ; 2-\mathrm{G}$.

Sawford, K., A. R. Vollman, and C. Stephen. 2013. A focused ethnographic study of Alberta cattle veterinarians' decision making about diagnostic laboratory submissions and perceptions of surveillance programs. PLoS One 8:e64811. https://doi.org/10.1371/ journal.pone.0064811.
Tracy, S. J. 2013. Qualitative Research Methods: Collecting Evidence, Crafting Analysis, Communicating Impact, 2nd edition. WileyBlackwell, Chichester, West Sussex.

Vaarst, M., B. Paarup-Laursen, H. Houe, C. Fossing, and H. J. Andersen. 2002. Farmers' choice of medical treatment of mastitis in Danish dairy herds based on qualitative research interviews. J. Dairy Sci. 85:992-1001. https://doi.org/10.3168/jds.S0022 -0302(02)74159-3.

van Asseldonk, M. A. P. M., R. J. Renes, T. J. G. M. Lam, and H. Hogeveen. 2010. Awareness and perceived value of economic information in controlling somatic cell count. Vet. Rec. 166:263-267. https://doi.org/10.1136/vr.b4713.

Vanclay, F. 2004. Social principles for agricultural extension to assist in the promotion of natural resource management. Aust. J. Exp Agric. 44:213-222. https://doi.org/10.1071/EA02139.

Vanclay, F., and G. Enticott. 2011. The role and functioning of cultural scripts in farming and agriculture. Sociol. Ruralis 51:256-271. https://doi.org/10.1111/j.1467-9523.2011.00537.x.

Wengraf, T. 2001. Qualitative Research Interviewing: Biographic Narrative and Semi-Structured Methods. Sage Publications Ltd., London, UK.

\section{ORCIDS}

Lauren McFarland ๑ https://orcid.org/0000-0001-5062-2148

Guy McGrath () https://orcid.org/0000-0002-8545-396X

Conor G. McAloon () https://orcid.org/0000-0002-4984-4031 